\title{
Evaluation of insertion torque of different orthodontic miniscrews: An in vitro study
}

\begin{tabular}{|c|c|}
\hline Hussein Ahmed Al- Obaidi* & Mangur Maghdid Nadir** \\
\hline \multicolumn{2}{|c|}{ Abstract } \\
\hline \multicolumn{2}{|c|}{$\begin{array}{l}\text { Background and objective: The purpose of this study was to evaluate the torque } \\
\text { insertion for drill and non drill techniques of two commercially available miniscrews. } \\
\text { Methods: Eighty mini screws (forty Dentos miniscrews/Korea and forty } 3 \mathrm{M} \text { miniscrews/ } \\
\text { USA), having the same length and diameter, were divided into two groups for each } \\
\text { type. Two techniques, non-drill and drill, were used. In drill techniques, manufacturer } \\
\text { recommended drill was used. Two bovine tibias were obtained. The first technique used } \\
\text { pre drill hole, which was made in the bone using the recommended bur (1.0 diameter). The } \\
\text { mini-screw was placed at } 9 \mathrm{~mm} \text { manually, then the remaining } 1 \mathrm{~mm} \text { was inserted through } \\
\text { digital torque meter. The same procedure was repeated but without a pilot hole. } \\
\text { Results: } 3 \mathrm{M} \text { miniscerws gave high torque insertion in two techniques. } \\
\text { Conclusion: The shape, thread design and tip geometry of miniscerw play an important } \\
\text { role in the torque insertion. } \\
\text { Keywords: Miniscerw, Dentos min screws, } 3 \mathrm{M} \text { miniscrews, Torque insertion. }\end{array}$} \\
\hline \multicolumn{2}{|l|}{ Introduction } \\
\hline \multicolumn{2}{|c|}{ 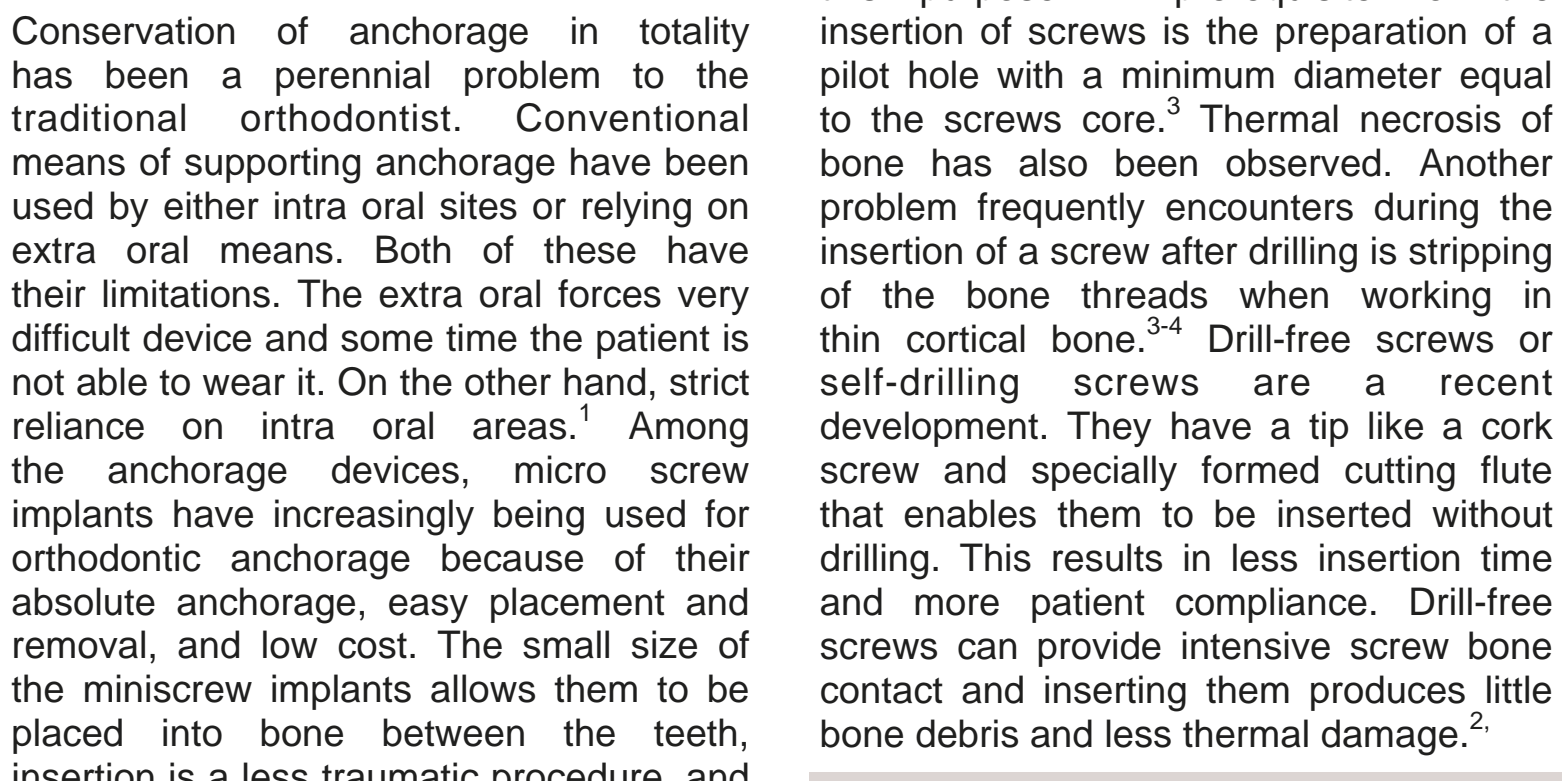 } \\
\hline \multirow{3}{*}{$\begin{array}{l}\text { as there is no osseointegration around } \\
\text { the screws but only fibrous integration. } \\
\text { However, a notable complication is } \\
\text { loosening of the screws even though they } \\
\text { consist of a biocompatible titanium alloy. } \\
\text { Drill screws are most commonly used for }\end{array}$} & \\
\hline & \\
\hline & \\
\hline
\end{tabular}

* Department of P.O.P, college of dentistry, university of Mosul, Mosul, I raq. 
mini-implants of similar diameters and length but due to differing manufacturer designs, diameters $1.8 \mathrm{~mm}$ and length 10 $\mathrm{mm}$. To create the groups, 40 mini-implants from each manufacturer were used. The sample was divided into four groups which were named as: Twenty $3 \mathrm{M}$ drilling (3MD) miniscrew with $1.8 \mathrm{~mm}$ in diameter and $10 \mathrm{~mm}$ length from (3M, USA) and twenty Dentos drilling (DD) miniscrew with $1.8 \mathrm{~mm}$ in diameter and $10 \mathrm{~mm}$ in length from (Dentos, Korea). Twenty dentos non drilling (DND) with $1.8 \mathrm{~mm}$ in diameter and $10 \mathrm{~mm}$ length from (Dentos, Korea ) and twenty $3 \mathrm{M}$ non drilling (3MND) miniscrew with
$1.8 \mathrm{~mm}$ in diameter and $10 \mathrm{~mm}$ in length from (3M), as summarized in Table 1. Bone specimen preparation

Two bovine tibias were obtained from the same animal (age: 18 months). It was cross-sectionally cut in relation to their long axis by electrical saw using normal saline as a coolant liquid to prevent any necrosis or heat generation created during cutting. After that, it was stored in an isotonic solution in a water bath $\left(38-39.3 C^{\circ}\right)$ to prevent dehydration of the bone. The length of two tibia bones was about $20 \mathrm{~cm}$. Each bone was cut into 10 pieces $(2 \mathrm{~cm}$ for each) as shown in Figure 2.

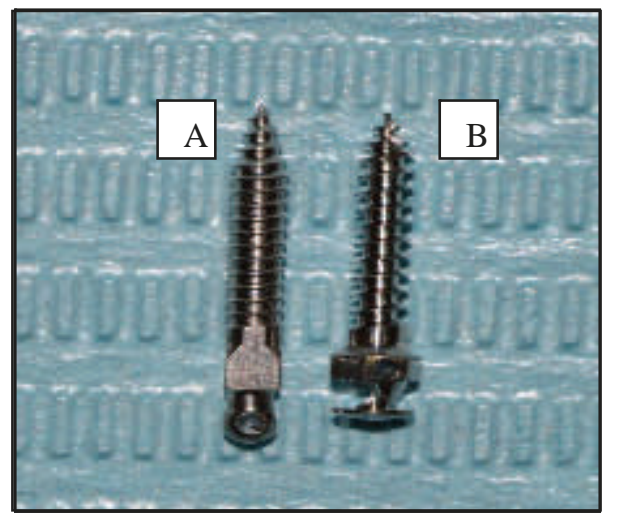

Figure 1: Two types of mini screws used (A: 3M/USA and B: Dentos /Korea).

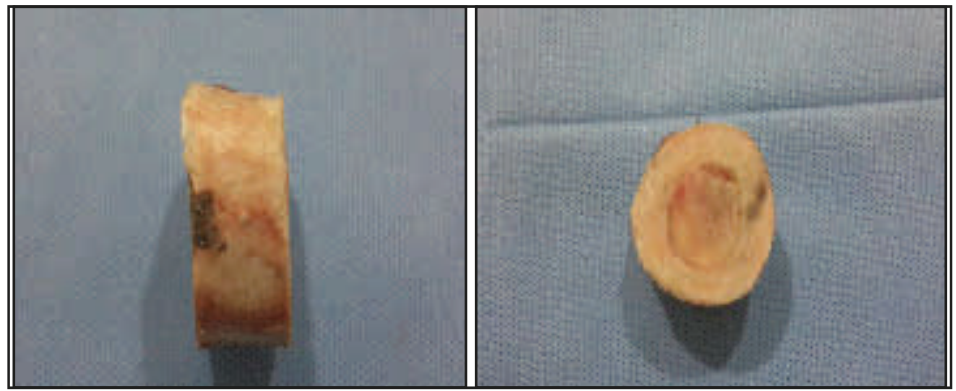

Figure 2 : Bone specimen preparation (2 cm in width).

Table 1: Description of mini-implants used in this study with division groups.

\begin{tabular}{|c|c|c|c|c|c|c|c|}
\hline \multicolumn{4}{|c|}{ Dentos (D)/Ti6Al4Va* } & \multicolumn{4}{|c|}{ 3M/ Ti6A14V* } \\
\hline $\begin{array}{l}20 \text { drill } \\
\text { (DD }\end{array}$ & & $\begin{array}{r}\text { 20nond } \\
\text { (NDL }\end{array}$ & illing & $\begin{array}{l}20 \text { drilli } \\
\text { (3M }\end{array}$ & & $\begin{array}{r}20 \text { nonc } \\
\text { (3M) }\end{array}$ & illing \\
\hline $\begin{array}{l}10 \mathrm{~mm} \\
\text { length }\end{array}$ & $\begin{array}{l}1.8 \\
\text { Diameter }\end{array}$ & $\begin{array}{l}\text { 10mm } \\
\text { length }\end{array}$ & $\begin{array}{l}1.8 \\
\text { diameter }\end{array}$ & $\begin{array}{l}\text { 10mm } \\
\text { length }\end{array}$ & $\begin{array}{l}1.8 \\
\text { diameter }\end{array}$ & $\begin{array}{l}\text { 10mm } \\
\text { length }\end{array}$ & $\begin{array}{l}1.8 \\
\text { diameter }\end{array}$ \\
\hline
\end{tabular}

*According to the manufacturer information. 
http:/ / dx.doi.org/ 10.15218/ zjms.2016.0003

Cortical bone measurement

The cortical bone thickness was measured for each of the bones using digital calipers (SanPaulo, Brazil) to decide on areas of mini screws insertion as standardization criteria. The cortical bone thickness less than $10 \mathrm{~mm}$, the bone piece was discarded. The cortical bone range from 10 to $12 \mathrm{~mm}$ and this thickness is enough for this study and allowed for adequate placement of the mini screw into cortical bone.

\section{Modification:}

Two modifications were done in this study as follows :

1- Modification in custom made device to receive the hand piece and to be sure that the insertion of mini screws as right angle with bone (Figure 3 ).

2- Modification in screw driver (Manufacturer supplied) with mini screw to be used with hand pieces (Figure 4).

Insertion of Mini screw:

The cortical bone was measured and identification was put in the area of mini screws insertion (standardization criteria). All mini screws were used in this study. A red indicator stopper (1mm thickness) was used at the last $1 \mathrm{~mm}$ distance of mini screws to stopped used of hand piece for insertion. The bone pieces were attached using a custom-made device designed to secure the sample and stabilize the sample during experimentally test. In addition, using leveling measurement to ensure that the insertion area was straight and mini screws insertion angle with it about 90 degrees. The custom made device modified his head to allow him to receive the handpiece. The surgical motor (W\&H for dental implant) $900 \mathrm{rpm}$ with $50 \mathrm{Ncm}$ was used for the mini screw insertion experiment.

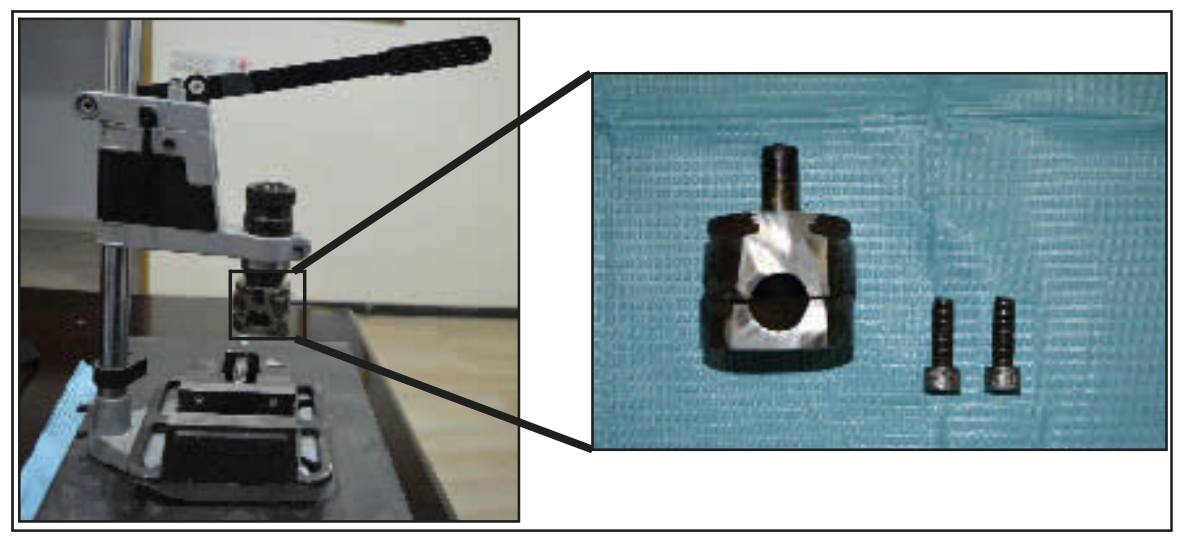

Figure 3: Custom made device after modification of the head to received hand piece and bone

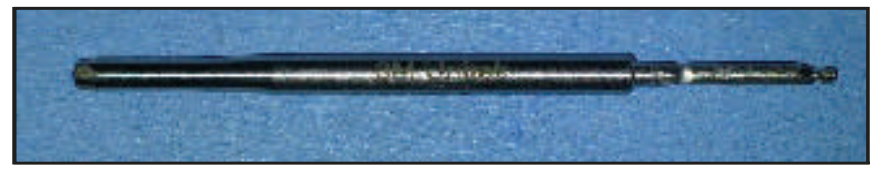

Figure 4: Modification head of screw driver to be used with handpiece. 
The insertion procedure was made in two ways (Figure 5). In the first way, before the insertion of mini screws, the pre drill hole was made in the bone with the use of the recommended bur (1.0 diameter) according to the manufacturer recommendation. After that, the insertion of mini screws was preformed with torque low speed hand piece and mini-screws insertion into bone alone. It was placed on the handpiece and drilling was performed self-irrigation with water. After the miniscrew had placed at length $9 \mathrm{~mm}$, then the digital torque meter (DID 4 digital torque meter/Korea) was used to insert the remaining $1 \mathrm{~mm}$ of miniscerw manually. After that, reading of maximum torque insertion was recorded. Then, anti-clockwise was used with same digital torque meter manually to remove the mini screws. The reading of maximum torque removal was also recorded. For non-drilling technique, the same procedure was repeated but without pilot hole, and direct insertion of mini screws was done.
The screw was directly inserted $9 \mathrm{~mm}$ by implant hand piece (red indicator stopper), then removed the stopper and stat manually insertion the remaining $1 \mathrm{~mm}$ was inserted in clockwise direction. After that, reading of maximum torque insertion was recorded using digital torque meter and remove the screw and also the removal torque was recorded with anti-clockwise direction. The differences between the torque values for each mini-scerws group and for two companies were analyzed using a two-way analysis of variance (ANOVA) using the statistical package for the social sciences (version 13.0) program. A ranking order was established using Tukey's test.

\section{Results}

The descriptive statistics that includes mean, standard deviation, standard error, minimum and maximum value of torque insertion and removal of $3 \mathrm{M}$ and Dentos mini screws for both drill and non drill techniques are listed in Table 3.

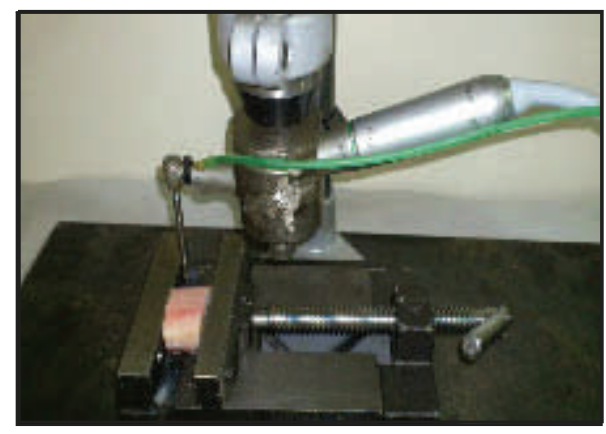

Figure 5: Experimental apparatus used for testing.

Table 3: Descriptive analysis and Duncan of multiple range test of tested Mini screws.

\begin{tabular}{lllll}
\hline Types and Techniques & Mean*** & Std. Deviation & $\mathbf{N}$ & $\boldsymbol{P}$ value \\
\hline 3MNDTI & $44.375^{\mathrm{a}}$ & 0.8789 & 20 & 0.05 \\
DNDTI & $38.285^{\mathrm{b}}$ & 0.6523 & 20 & 0.05 \\
$3 \mathrm{MDTI}$ & $37.465^{\mathrm{c}}$ & 0.7407 & 20 & 0.05 \\
DDTI & $32.220^{\mathrm{d}}$ & 0.5238 & 20 & 0.05 \\
\hline $\begin{array}{l}{ }^{*} \text { Mean unit }(\mathrm{N} / \mathrm{mm}) \\
\text { 3MNDTI: 3M non drill torque insertion }\end{array}$ & $\begin{array}{l}\text { **Different letters mean significantly different at } P £ 0.05 . \\
\text { 3MDTI: 3M drill torque insertion }\end{array}$ & $\begin{array}{l}\text { DNDTI: Dentos non drill torque insertion } \\
\text { DDTI: Dentos drill torque insertion }\end{array}$ \\
\hline
\end{tabular}




\section{Discussion}

The experimental method applied in this study used a bovine bone because it is difficult to test the torque in vivo, and it was problematic when it came to extracting the sample from human cadavers. ${ }^{6}$ In addition, this challenge occurs because of the variations in thickness and density of the cortical bone from the site of extraction. Hence, the amount of torque cannot be compared. ${ }^{7}$ The cortical bone thickness used in this study has covered all mini screws length as one of standardization procedures and to prevent this factor to affect the torque insertion and removal for all types of mini screws used. Torque is closely related to the factors that determine the stability of miniscrews, such as bone density $^{8-9}$ and cortical bone thickness. ${ }^{10}$ In addition, the torque value is frequently used as an indirect method to assess the stability of an implant or miniscrew. ${ }^{11-12}$ In this research, non drilling groups showed significant increase of torque insertion in $3 \mathrm{M}$ mini screws in comparison with Dentos type. This result is due to the geometric shape of 3M type (cylindrical shape) which require a longer period of time to penetrate the bone than the tapered type screw (Dentos). This result disagrees with Jung-Y. Ch et al $2008,{ }^{13}$ who found that the tapered type gave a high torque insertion than cylindrical. This is particularly true when penetrating the cortical bone. For this reason, selecting a bone contained cortical bone was enough for all length of mini screws, in addition, the length of screws and the dimension were the same in both types. The Dentos mini screws gave a low rate of torque insertion compared with $3 \mathrm{M}$. This is due to the morphologic characteristics of the screw that are related to the driver generating a change in torque on the same side. Many causes make the Dentos mini screw giving low torque insertion and it includes knife edge of threads, best pitch and valley of thread and self drilling shape of tip of mini screws (according to manfacturer design). These features reduce the stresses on the bone
During insertion. However, further research is needed to prove this. Although these morphological features of mini screws help the dentist to insert the mini screw too easily and decrease the bone necrosis during insertion because the less amount of pressure will be applied during procedure. Research has showed that the mini screw giving low torque value during insertion has less amount of primary stability when compared with high torque one when the immediate load will be applied. ${ }^{14}$ From another hand, another research showed that after a period of time (secondary stability) the torque removal was the same with different shape of mini screw because the osseointegration occurred and the shape of mini screw became not important one as in primary stability. ${ }^{15-18}$ In drilling group, the mean of torque insertion was significantly different between groups and between the two types of mini screws but the difference between groups was very small. Although many biomechanical studies have reported that insertion torque affects screw stability, it is difficult to prove that the insertion torque is proportional to the stability of mini-screws. ${ }^{14}$ Lawes et al. suggested that a high insertion torque of a tapered bone screw decreases loosening at the bone interface. ${ }^{14,19}$ This is supported by our results, which showed that $3 \mathrm{M}$ mini-screws provide better primary stability regardless of the bone type. However, when torque values are excessive (more than the bone can withstand), bone cracks or bone necrosis may occur.$^{14,20}$ In this study, the local maximum torque appeared at about 60 s in the mini-screw insertion process, indicating that the cortical bone shell was penetrated, causing the torque to gradually increase. The extremely high torque insertion value for $3 \mathrm{M}$ mini-screws might reach the screw/implant inserted torque border and indicated that the physiologic limit was exceeded might induce bone resorption. The mini-screw mobilization mechanisms on the surrounding bone tissue might be related to the insertion and 
removal torques, and energy required for insertion and removal. ${ }^{2}$ However, the high insertion torque of the $3 \mathrm{M}$ design could lead to stress in the bone tissue. Some study on finite element analysis showed when some types of mini screws were examined micromotion at the screw/bone interface and bone strain development. Since the resistance of the micro-motion at the mini-screw/bone interface depends on the initial mechanical fixation between the screw and bone, it is likely that high ${ }^{14}$ and micro-motion might be caused by early loading. ${ }^{14,21}$ The small displacements also suggest that a mini-screw can be immediately loaded, thereby decreasing chair time for clinicians and treatment time for patients. A critical issue related to skeletal anchorage realized with orthodontic mini-screws is the mechanical behavior of mini-screws inserted into the bone. Strain is accepted as the mechanical stimuli for bone remodeling around an implant. $^{22}$ Frost $(1994)^{23}$ suggested that bone remodeling is initiated at a critical strain level (the mechano-static theory) and that micro damage arises in normal lamellar bone when the strain exceeds 4000 micro strain. ${ }^{23}$ An optimal mini-screw design for avoiding failure and minimizing the strain value in the surrounding bone to reduce screw loosening is needed. ${ }^{22}$ More living tissue studies are required for a better understanding of secondary stability, which includes osteo-integration and physiological reactions of the bone to external forces. Otherwise, suitable torque values should be continuously for evaluated to minimize bone damage in the human body and act as sufficient anchorage for orthodontic forces within a range that the bone sufficient support.

\section{Conclusion}

3M mini screws showed high insertion torque than Dentos one. The geometry of mini screws plays an important role in torque insertion. The thread design has a direct effect on the insertion of mini screws. The shape and design of the tip of mini screws may increase or decrease the insertion torque.

\section{Conflicts of interest}

The authors report no conflicts of interest.

\section{References}

1. Gracco A, Cirignaco A, Cozzani M, Boccaccio A, Pappalettere C, Vitale G. Numerical/ experimental analysis of the stress field around miniscrews for orthodontic anchorage. Eur.J.Orthod 2009; 31: 12-20.

2. Kim WJ, Ahn SJ, Chang Y. Histomorphometric and mechanical analysis of the drill free screw as orthodontic anchorage, Am J Orthod Dentofacial Orthop 2005; 128:190-4.

3. Heidemann W, Gerlach KL, Grobel KH, Kollner HG: Drill free screws. A new form

of osteosynthesis screws. J Cranio Max Surg 1998; 26: 163-8.

4. Dalstra M, Cattaneo PM, Melsen B. Load transfer of miniscrews for orthodontic anchorage, Orthodontics 2004;1:53-62.

5. Park SH, Yen S, Jeoung SH. Histological and biomechanical characteristics of orthodontic selfdrilling and self-tapping microscrew implants. Korean J Orthod 2006; 36:295-307.

6. Lim SA, Cha JY, Hwang CJ. Insertion torque of orthodontic miniscrews according to changes in shape, diameter and length. Angle Orthod 2008; 78:234-40,

7. Jian-H Yu, Yang-S L, Wen-J Ch, Yau- Z, Ch, Chun-L. Mechanical Effects of Micro-thread Orthodontic Mini-screw Design on Artificial Cortical Bone. Journal of Medical and Biological Engineering 2012; 34(1): 49-55.

8. Friberg B, Sennerby L, Roos J, Johansson P, Strid CG, Lekholm U. Evaluation of bone density using cutting resistance measurements and microradiography: an in vitro study in pig ribs. Clin Oral Implants Res 1995;6:164-71.

9. Ikumi N, Tsutsumi S. Assessment of correlation between computerized tomography values of the bone and cutting torque values at implant placement: a clinical study. Int J Oral Maxillofac Implants 2005;20:253-60.

10. Niimi A, Ozeki K, Ueda M, Nakayama B. A comparative study of removal torque of endosseous implants in the fibula, iliac crest and scapula of cadavers: a preliminary report. Clin Oral Implants Res 1997;8:286-9.

11. Beer A, Gahleitner A, Holm A, Tschabitscher M, Homolka P. Correlation of insertion torques with bone mineral density from dental quantitative CT in the mandible. Clin Oral Implants Res 2003;14:616-20.

12.O'Sullivan D, Sennerby L, Meredith N. Influence of implant taper on the primary and secondary stability of osseointegrated titanium implants. Clin Oral Implants Res 2004;15:474-80. 
13. Jung $Y$ Ch, Tae MY, Chung $H$. Insertion and removal torques according to orthodontic miniscrew design. Korean J Orthod 2008;38(1):5-12.

14. Song $Y$, Cha $Y$, Hwang C. Mechanical characteristics of various orthodontic mini-screws in relation to artificial cortical bone thickness. Angle Orthod 2007; 77:979-85

15. Kuroda S, Sugawara Y, Deguchi T, Kyung HM, Takano Yamamoto T. Clinical use of miniscrew implants as orthodontic anchorage: success rates and postoperative discomfort.

Am J Orthod Dentofacial Orthop 2007;131:9-15.

16. Miyawaki S, Koyama I, Inoue M, Mishima K, Sugahara T, Takano-Yamamoto $\mathrm{T}$. Factors associated with the stability of titanium screws placed in the posterior region for orthodontic anchorage. Am J Orthod Dentofacial Orthop 2003;124:373-8.

17. Park HS, Jeong SH, Kwon OW. Factors affecting the clinical success of screw implants used as orthodontic anchorage. Am J Orthod Dentofacial Orthop 2006;130:18-25.

18. Chen YJ, Chen YH, Lin LD, Yao CC. Removal torque of miniscrews used for orthodontic anchorage--a preliminary report. Int $\mathrm{J}$ Oral Maxillofac Implants 2006;21:283-9.

19. Lawes TJ, Scott JC, Goodship AE. Increased insertion torque delays pin-bone interface loosening in external fixation Effects of Microthread Design on Artificial Bone 55 with tapered bone screw J.Orthop.Trauma 2004;18:617-22.

20. Motoyoshi M , Hirabayashi M , Uemura M , Shimizu N . Recommended placement torque when tightening an orthodontic mini-implant. Clin.Oral Implants Res 2006; 17:109-14.

21. Norton MR. Marginal bone levels at single tooth implants with a conical fixture design. The influence of surface macro-and microstructure. Clin. Oral Implants Res 1998; 9:91-9.

22. Lin $\mathrm{C}, \mathrm{Yu} \mathrm{H}$, Liu $\mathrm{H}$, Lin $\mathrm{C}$, Lin $\mathrm{Y}$. Evaluation of the relative contributions of orthodontic mini-screw design factors using FE analysis and the Taguchi method. J. Biomech 2010;43:2174-81.

23. Frost HM. Woff's law and bone's structural adaptations to mechanical usage: an overview for clinicians. Angle Orthod 1994; 64:175-88. 